\title{
Obstructive bronchial hamartoma
}

\section{George Rakovich MD, Denise Ouellette MD}
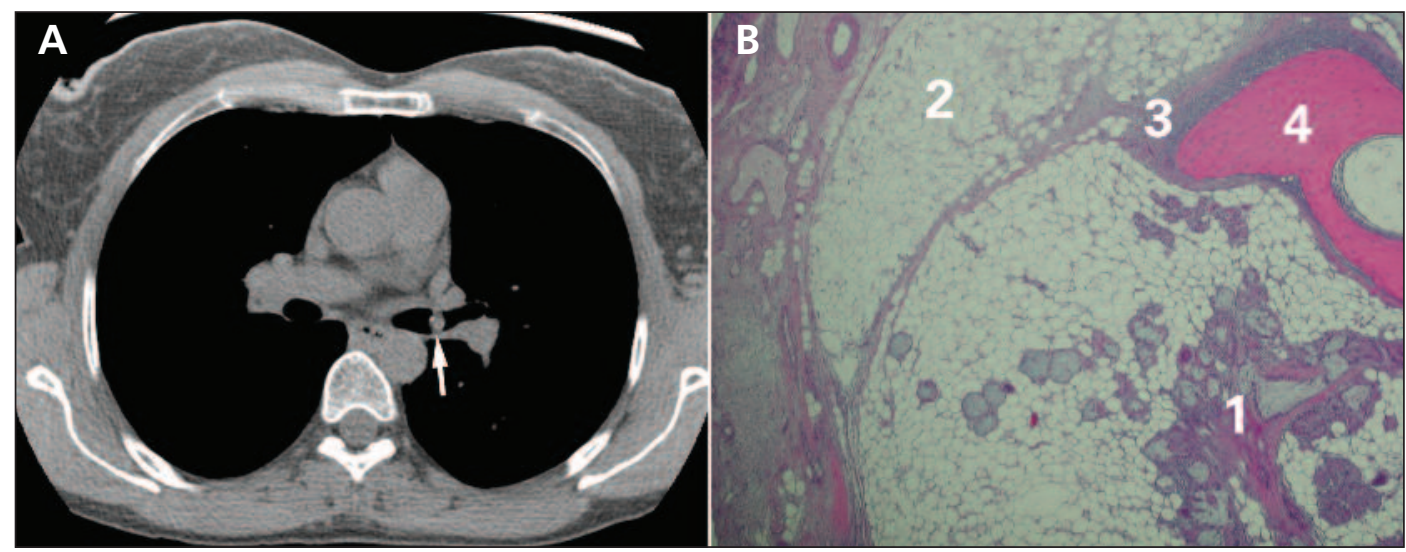

Figure 1: (A) Computed tomographic scan of the chest of a 47-year-old woman with persistent cough, showing an endobronchial lesion obstructing the left main bronchus. Subtle calcification is visible. (B) Photomicrograph of the bronchial hamartoma containing typical features of bronchial glands (1), fat (2), cartilage (3) and bone (4) (hematoxylin-eosin $\times 20$ ).

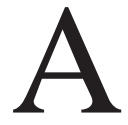
47-year-old woman presented with a persistent cough of two months' duration. She was a former smoker of 10 packyears, who had recently been treated with antibiotics for an episode of pneumonia. Her physical examination (including auscultation of lungs) was normal, as was a chest radiograph. In light of her history of smoking, we ordered computed tomography of the chest, which showed a lesion containing subtle calcification in the left main bronchus (Figure 1A). Bronchoscopy showed a pedunculated polypoid lesion covered by smooth, normal-appearing mucosa obstructing the distal portion of the left main bronchus. Biopsy was nondiagnostic. Endoscopic snare excision using a flexible bronchoscope (Appendix 1, video available at www.cmaj.ca/lookup/suppl/doi:10.1503 /cmaj.110134/-/DC1) led to a diagnosis of a benign hamartoma containing bronchial glands, fat, cartilage and bone (Figure 1B). Postoperative bronchoscopy showed a patent lumen and a wellhealing eschar. Our patient was free of symptoms at her three-month follow-up appointment.

An obstructive endobronchial lesion should be suspected in patients with persistent cough with or without hemoptysis, fixed wheezing on physical examination, or recurrent localized pulmonary infection or atelectasis on chest radiography. ${ }^{1,2}$
Malignant growth in lungs is the most frequent cause of bronchial obstruction in adults, with benign tumours accounting for a minority of instances. ${ }^{2}$ Hamartomas are the most common benign endobronchial lesions. ${ }^{2}$ In many instances, symptomatic endobronchial hamartomas and other benign lesions of the bronchi are amenable to endoscopic resection using either a flexible or rigid bronchoscope, the latter being particularly useful for piecemeal extraction of tumour fragments following laser fulguration. ${ }^{3}$ Our case report illustrates that the cause of bronchial obstruction is not always malignant and that endoscopic techniques may spare patients the morbidity of thoracotomy and airway resection. ${ }^{1,2}$ The prognosis in completely resected lesions is excellent. ${ }^{1,2}$

\section{References}

1. Cosio BJ, Villena V, Echave-Sustaeta J, et al. Endobronchial hamartoma. Chest 2002;122:202-5.

2. Prince JS. Hamartoma. In: Duhamel DR, Harrell JH, editors. Clinical atlas of airway diseases bronchoscopy, radiology, and pathology. 1st ed. Philadelphia (PA): Elsevier Saunders; 2005. p. 85-6.

3. Kwon YS, Kim H, Koh WJ, et al. Clinical characteristics and efficacy of bronchoscopic intervention for tracheobronchial leiomyoma. Respirology 2008;13:908-12.
Competing interests: None declared.

This article has been peer reviewed.

Affiliations: From the Division of Thoracic Surgery, Hôpital

Maisonneuve-Rosemont, University of Montreal, Montréal, Que.

Correspondence to: Dr. George Rakovich, george.rakovich@umontreal .ca

CMAJ 2011. DOI:10.1503 /cmaj.110134 